\title{
Comparison of leaves and stems of Paederia scandens (Lour.) Merr. in tolerance to low temperature
}

\author{
M.L. CAI, Q.L. ZHANG, X.T. ZHENG, J.J. ZHAI, and C.L. PENG ${ }^{+}$ \\ Guangzhou Key Laboratory of Subtropical Biodiversity and Biomonitoring, Guangdong Provincial Key Laboratory \\ of Biotechnology for Plant Development, College of Life Sciences, South China Normal University, 510631 \\ Guangzhou, China
}

\begin{abstract}
Low temperature is an important environmental factor that affects plant growth and development. To determine the adaptability of different organs of Paederia scandens (Lour.) Merr. to low temperature, the chlorophyll (Chl) fluorescence parameters as well as the Chl, malondialdehyde (MDA), soluble sugar, and anthocyanin contents of leaves and stems were measured under low temperature. The results confirmed that the Chl fluorescence parameters and Chl content of the leaves and stems of $P$. scandens tended to decrease consistently, while the MDA content increased, and the change range of the stems was much lower than that of the leaves. The soluble sugar and anthocyanin contents rapidly increased in the leaves and stems to cope with low temperature. Our results suggest that stems are more tolerant than leaves during winter and may continue to grow during that time, which could provide theoretical guidance for clonal propagation of plants to study stem tolerance in the future.
\end{abstract}

Additional key words: cold; non-leaf photosynthetic organs; osmoprotectants; photosynthesis.

\section{Introduction}

Plants compose a large class of organisms in nature, and their growth and development are closely related to environmental changes. In particular, temperature is a primary factor that affects plant growth, development, and yield (Hatfield and Prueger 2015).

As an important abiotic stress, low temperature limits plant growth, reduces crop yields, and even results in plant death (Sanghera et al. 2011, Sharma et al. 2015). To adapt to adverse environmental conditions, plants have evolved a series of adaptive and self-protection strategies that involve many biochemical and physiological changes (Bressan et al. 2009, Liu et al. 2012). Many changes including alterations to membrane permeability, increase of the abundance of osmotic regulators and antioxidants (Wu et al. 2008, Korn et al. 2010), changes in photosynthesis capabilities (Cui et al. 2019), and regulation of endogenous hormone contents, occur in response to low temperatures (Sharma et al. 2015, Zwack and Rashotte 2015, de Zelicourt et al. 2016).

Under low temperature, osmoprotectants, which include soluble sugars, proline, and other substances, are considered crucial materials involved in plant adaptations to the various stresses. Increases in these substances can effectively promote the ability of osmotic regulation and prevent excessive dehydration of protoplasts (Vágújfalvi et al. 1999, Lu et al. 2006). Malondialdehyde (MDA), a product of membrane lipid peroxidation, can aggravate membrane lipid peroxidation. MDA accumulation indicates the degree of plant damage caused by stress and reflects the strength of membrane peroxidation (Sun et al. 2004). In addition, low temperature can also cause oxidative stress, such as the accumulation of reactive oxygen species (ROS) in cells. The accumulation of ROS can result in membrane lipid peroxidation and the destruction of membrane structure, leading to leakage of intracellular components (Chen et al. 2000, Shahandashti et al. 2013).

Leaves are the main photosynthetic organ for plants. Many studies have focused primarily on the response mechanism of leaves (Kuk et al. 2006). Some adverse environments, such as insect bites, drought, and other conditions can lead to plant leaf wilting and litter while other plant parts can retain (Vanderklein and Reich 2000, Chen et al. 2001). At present, some non-leaf organs, including stems, bracts, and ears, have also actual or

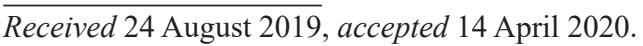

${ }^{+}$Corresponding author; e-mail: pengchl@scib.ac.cn

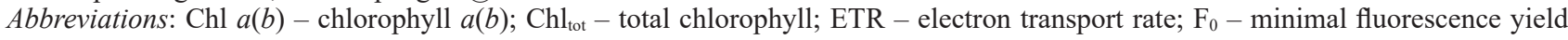
of the dark-adapted state; $\mathrm{F}_{\mathrm{m}}-$ maximal fluorescence yield of the dark-adapted state; FM - fresh mass; $\mathrm{F}_{\mathrm{m}}{ }^{\prime}-$ maximal fluorescence yield of the light-adapted state; $F_{\mathrm{s}}$ - steady-state fluorescence yield; $\mathrm{F}_{\mathrm{v}} / \mathrm{F}_{\mathrm{m}}$ - maximal quantum yield of PSII photochemistry; MDA malondialdehyde; ROS - reactive oxygen species; TBA - thiobarbituric acid; TCA - trichloroacetic acid; $\Phi_{\mathrm{PSII}}-$ effective quantum yield of PSII photochemistry.

Acknowledgments: This work was funded by the National Natural Science Foundation of China (31870374, 31570398) and the National Key R\&D Program of China (2017YFC1200105).
} 
potential photosynthetic capacity (Aschan and Pfanz 2003). In wheat, photosynthesis of leaves was inhibited; the main contribution factor of grain yield may be photosynthesis from ear under drought (Tambussi et al. 2007). Zhan et al (2014) found that photosynthesis of non-leaf organs made an important contribution to the formation of seed yield when cotton fruit was under water stress in the developmental stage. Studies have shown that nonleaf organ stems accounted for a large proportion of vine and could form or contain Chl, which plays an important role in the growth and development of plants (Yang et al. 2006). However, few studies have investigated the possible response mechanism in stems of vine under stress of adversity.

Paederia scandens (Lour.) Merr., a climbing vine, is a good source of nutrients and has medicinal function. This species contains an abundance of ascorbic acid, rich mineral elements, and complete amino acids (Zhang 2006). Whether planted from seeds or propagated via cuttings, this species has strong vitality and reproductive capabilities. In addition, $P$. scandens exhibits abnormal tolerance to environmental conditions, such as cold resistance and shade resistance, and this species is widely distributed in Guangdong, Guangxi, and other provinces in China. Many studies have focused mainly on analyzing the pharmacological and chemical components of $P$. scandens, such as flavonoids (Nariyuki et al. 1990), and identifying its volatile oil compounds (Ma et al. 2000, Yin et al. 2009). However, information on the morphological, physiological, and ecological characteristics of this species is limited. Therefore, the purpose of this study was to explore the physiological responses of different organs of $P$. scandens to low temperature and whether the trend and range of change are consistent. We analyzed several physiological indexes, including chlorophyll fluorescence parameters, osmoprotectants, and chlorophyll contents. The results would provide theoretical guidance for clonal propagation of plants to study stem tolerance in the future.

\section{Materials and methods}

Plant materials, cultivation, and low-temperature treatment: Plant material was collected from South China Agricultural University, Guangzhou, China. Collected plant material was cut into 8-10-cm lengths with two internodes, and cultivated using hydroponics in an incubator that had a light intensity of $100 \mu \mathrm{mol}\left(\right.$ photon) $\mathrm{m}^{-2} \mathrm{~s}^{-1}$, a light period of $16 \mathrm{~h}$, a dark period of $8 \mathrm{~h}$, a humidity of approximately $65 \%$, and a temperature of $25^{\circ} \mathrm{C}$. After the seedlings were cultivated for half a month, they were transplanted into pots, after which they grew for one month. Similarly appearing seedlings, which were approximately $45 \mathrm{~cm}$ in length, were subjected to low-temperature treatment at $16^{\circ} \mathrm{C}$. Relevant physiological indexes were measured by collecting leaf and stem materials at 0 and $10 \mathrm{~d}$ after treatment, with each material replicated three times.

Analysis of Chl fluorescence: Chl fluorescence was tested using a PAM-2100 device (Walz, Germany) with a PPFD of $800 \mu \mathrm{mol} \mathrm{m} \mathrm{m}^{-2} \mathrm{~s}^{-1}$. The plants were placed in dark conditions for $20 \mathrm{~min}$. The maximal quantum yield of PSII photochemistry $\left(\mathrm{F}_{\mathrm{v}} / \mathrm{F}_{\mathrm{m}}\right)$ was calculated by the instrument as $\mathrm{F}_{\mathrm{v}} / \mathrm{F}_{\mathrm{m}}=\left(\mathrm{F}_{\mathrm{m}}-\mathrm{F}_{0}\right) / \mathrm{F}_{\mathrm{m}}$ (Oxborough and Baker 1997), where $F_{0}$ is the minimal fluorescence yield of the darkadapted state, and $\mathrm{F}_{\mathrm{m}}$ is the maximal fluorescence yield of the dark-adapted state. The steady-state Chl fluorescence $\left(\mathrm{F}_{\mathrm{s}}\right)$, maximal fluorescence yield of the light-adapted state $\left(\mathrm{F}_{\mathrm{m}}{ }^{\prime}\right)$, and effective quantum yield of PSII photochemistry $\left(\Phi_{\text {PSII }}\right)$ of the leaves and stems were measured. The $\Phi_{\text {PSII }}$ was calculated as $\Phi_{\text {PSII }}=\Delta \mathrm{F} / \mathrm{F}_{\mathrm{m}}{ }^{\prime}=\left(\mathrm{F}_{\mathrm{m}}{ }^{\prime}-\mathrm{F}\right) / \mathrm{F}_{\mathrm{m}}{ }^{\prime}$ (Genty et al. 1989), and the electron transport rate (ETR) was calculated as $\mathrm{ETR}=\Phi_{\mathrm{PSII}} \times \mathrm{PPFD} \times 0.85 \times 0.5$, where PPFD is the actinic light intensity of $800 \mu \mathrm{mol} \mathrm{m} \mathrm{m}^{-2} \mathrm{~s}^{-1}, 0.85$ is the effective leaf absorption, and 0.5 is the fraction of absorbed quanta used by PSII (Melis et al. 1987).

Chl content: Leaves $(0.05 \mathrm{~g})$ and stems $(0.05 \mathrm{~g})$ from the $3^{\text {rd }}$ to $5^{\text {th }}$ nodes (starting at the top) were placed into $10-\mathrm{mL}$ centrifuge tubes and then crushed into a powder in liquid nitrogen. Afterward, $4 \mathrm{~mL}$ of $80 \%$ acetone was added, and the mixture was subsequently incubated in the dark at $4^{\circ} \mathrm{C}$ for $24 \mathrm{~h}$. The supernatant was measured at wavelengths of $663 \mathrm{~nm}$ and $645 \mathrm{~nm}$, with $80 \%$ acetone used as a blank control (Shimadzu, Tokyo, Japan). The contents of Chl $a$, $\mathrm{Chl} b$, and the total Chl were calculated by a UV-Vis 2450 spectrophotometer (Shimadzu, Tokyo, Japan) in accordance with the methods of Wellburn (1994):

Chl $a\left[\mu \mathrm{g} \mathrm{mL}^{-1}\right]=12.21 \times \mathrm{A}_{663}-2.81 \times \mathrm{A}_{645}$

$\mathrm{Chl} b\left[\mu \mathrm{g} \mathrm{mL}^{-1}\right]=20.13 \times \mathrm{A}_{645}-5.03 \times \mathrm{A}_{663}$

Total Chl $\left[\mu \mathrm{g} \mathrm{mL}^{-1}\right]=\mathrm{Chl} a+\mathrm{Chl} b$

MDA and soluble sugar contents: MDA and soluble sugar contents were determined by the thiobarbituric acid (TBA) method (Zhao et al. 1994). Leaves (0.05 g) and stems $(0.05 \mathrm{~g})$ were crushed into a homogenate in conjunction with a small amount of quartz sand and $2 \mathrm{~mL}$ of precooled $10 \%$ trichloroacetic acid (TCA) in a mortar. The homogenate was then centrifuged at 10,000 rpm for $10 \mathrm{~min}$ to obtain the supernatant, after which $1 \mathrm{~mL}$ of the supernatant and $1 \mathrm{~mL}$ of $0.6 \%$ TBA solution were mixed together. The solution was heated in boiling water for $30 \mathrm{~min}$ and then quickly cooled in an ice bath, after which its absorbance at wavelength of 600,532 , and $450 \mathrm{~nm}$ was measured by a UV-Vis 2450 spectrophotometer. The following equations were subsequently used:

$\operatorname{MDA}\left[\mu \mathrm{mol} \mathrm{L}^{-1}\right]=6.45 \times\left(\mathrm{A}_{532}-\mathrm{A}_{600}\right)-0.56 \times \mathrm{A}_{450}$

soluble sugar $\left[\mathrm{mmol} \mathrm{L}^{-1}\right]=11.71 \times \mathrm{A}_{450}$

The anthocyanin content was analyzed according to the methods of a previous report (Zhang et al. 2016). Leaves $(0.05 \mathrm{~g})$ and stems $(0.05 \mathrm{~g})$ were soaked in $2 \mathrm{~mL}$ of $1 \%$ methanol: $\mathrm{HCl}(99: 1, \mathrm{v} / \mathrm{v})$ at $4^{\circ} \mathrm{C}$ for $6-12 \mathrm{~h}$ in the dark. Afterward, $1 \mathrm{~mL}$ of chloroform and $0.5 \mathrm{~mL}$ of pure water were added to the solution, after which mixture was fully blended and allowed to separate into layers. The upper layer comprised anthocyanins, and the lower layer comprised Chl. The absorption spectrum of the upper layer 
was scanned with a UV-Vis 2450 spectrophotometer at wavelengths of 400-700 nm, after which the absorbance of the anthocyanins at $530 \mathrm{~nm}$ was determined. The anthocyanin content was calculated via the standard curve of cyanidin-3-O-glucose.

Statistical analysis: The data represent the means \pm standard deviations (SD) of three samples in the experiment. The statistical analysis and multiple comparisons of the data were performed by IBM SPSS Statistics 19.0 software (SPSS, Chicago, IL, USA). Duncan's multiple comparison methods were used to test the significance of the different physiological indexes of $P$. scandens leaves and stems under low temperature, and differences were considered significant at $p<0.05$. Figures were constructed by SigmaPlot 12.5 software (Systat Software, San Jose, CA, USA).

\section{Results}

Phenotypic changes of leaves and stems: After $10 \mathrm{~d}$ of treatment, the leaves of $P$. scandens displayed a yellowing phenomenon. Leaf margins and petioles showed reddening, but it was not obvious on the whole leaves (Fig. 1A). The reddening phenomenon of the stems was obvious after

$0 d$
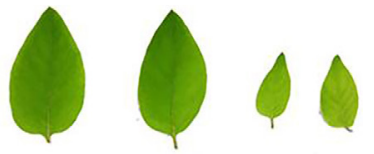

$10 d$

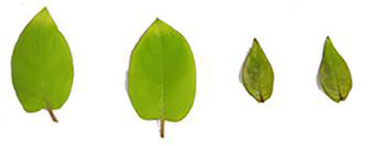

$B$

$0 d$
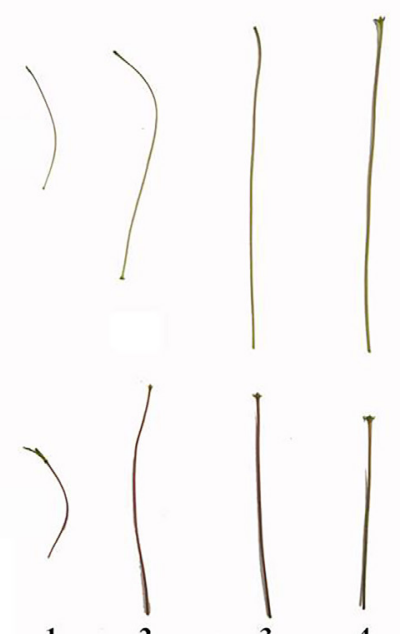

Fig. 1. Apparent changes in leaves and stems of Paederia scandens under low temperature for 0 and $10 \mathrm{~d}\left(\mathrm{~T}=16^{\circ} \mathrm{C}\right)$. $(A)$ Changes in the leaves of plants. $(B)$ Changes (from left to right) of the first internode, second internode, third internode and fourth internode of the stems. low-temperature treatment, and the reddening of the stems was much greater than that of the leaves (Fig. 1B).

Chl fluorescence parameters: When plants are under optimal conditions, the value of $\mathrm{F}_{\mathrm{v}} / \mathrm{F}_{\mathrm{m}}$ generally ranges from $0.75-0.85$, but it obviously decreases under stress or injury (He et al. 2005). We found that the $\mathrm{F}_{\mathrm{v}} / \mathrm{F}_{\mathrm{m}}$ of the stems and leaves of $P$. scandens tended to decrease after $10 \mathrm{~d}$ of treatment, which was most significant in the leaves $(18.3 \%)$ and was approximately 9 times that of the stems $(2.2 \%)$ (Fig. $2 A$ ). Here, $\Phi_{\text {PSII }}$ represents the actual light energy conversion efficiency of PSII and is also positively correlated with the activity of PSII. Under low temperatures, the decreasing trend of the $\Phi_{\text {PSII }}$ of the stems and leaves was the same as that of $F_{v} / F_{m}$, and the range of decrease was much greater in the leaves than that in the stems (Fig. 2B). The ETR reflects the activity of PSII and is directly related to the photosynthetic rate of plants. The ETR of both the stems and leaves tended to decrease under low temperature, which was consistent with the trend of the $\Phi_{\text {PSII }}$ (Fig. 2C).

Chl content: As one of the important indexes of photosynthesis, the $\mathrm{Chl}$ content can reflect certain physiological

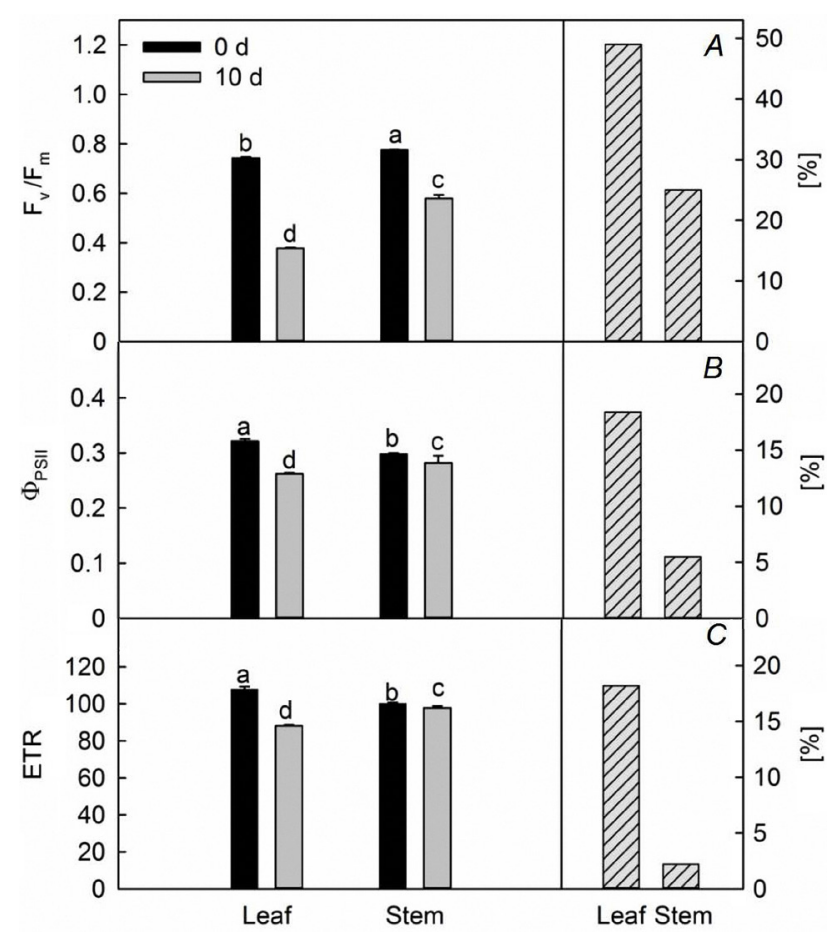

Fig. 2. Chlorophyll fluorescence parameters of leaves and stems of Paederia scandens under low temperature for 0 and $10 \mathrm{~d}\left(\mathrm{~T}=16^{\circ} \mathrm{C}\right)($ left $) .(A) \mathrm{F}_{\mathrm{v}} / \mathrm{F}_{\mathrm{m}}-$ maximal quantum yield of PSII photochemistry. $(B) \Phi_{\text {PSII }}$ - PSII maximum photochemical efficiency. (C) ETR - electron transport rate. The comparison of the increased percentage in chlorophyll fluorescence parameters of the leaves and stems under low-temperature treatment for $10 \mathrm{~d}$ (right). Values are means $\pm \mathrm{SD}(n=3)$. Statistical significance was determined using one-way ANOVA with Duncan's multiple comparison test $(p<0.05)$. 
responses to the external environment (drought, low temperature, light) and functions in light absorption and light energy conversion (Xu et al. 2000). The Chl contents in the leaves and stems of $P$. scandens tended to decrease under low temperature. The degree of reduction in $\mathrm{Chl} b$ and total $\mathrm{Chl}$ contents was lesser in the stems than that in the leaves (Fig. 3B,C), while the Chl $a$ content was similar in the stems and leaves (Fig. $3 A$ ), which indicates that the $\mathrm{Chl}$ synthesis in the leaves under low temperature stress was greater than that in the stems. Moreover, the $\mathrm{Chl} a / b$ radio of the stem decreased while that of the leaves increased (Fig. 3D).

MDA content: When plants are under stress, large amounts of ROS are produced and accumulate within the plant. MDA is a degradation product formed from the attack of
ROS on membrane lipids and is an important manifestation of the degree of membrane structure and loss of function. We measured the changes in MDA contents in the leaves and stems for $10 \mathrm{~d}$ and found that the MDA contents significantly increased. The content of MDA in the stems increased by $25 \%$, the content in the leaves increased by $84 \%$, and that in the leaves was nearly 4 times that in the stems (Fig. 4).

Anthocyanin content: Under low-temperature stress, anthocyanins accumulated in the leaves and stems, and the anthocyanin content in the stems was much greater than that in the leaves, the contents significantly increased by 50 and $43 \%$, respectively (Fig. 5). This finding is consistent with the phenotype observed after $10 \mathrm{~d}$ of treatment, the stems clearly turned red, while the leaves did not.
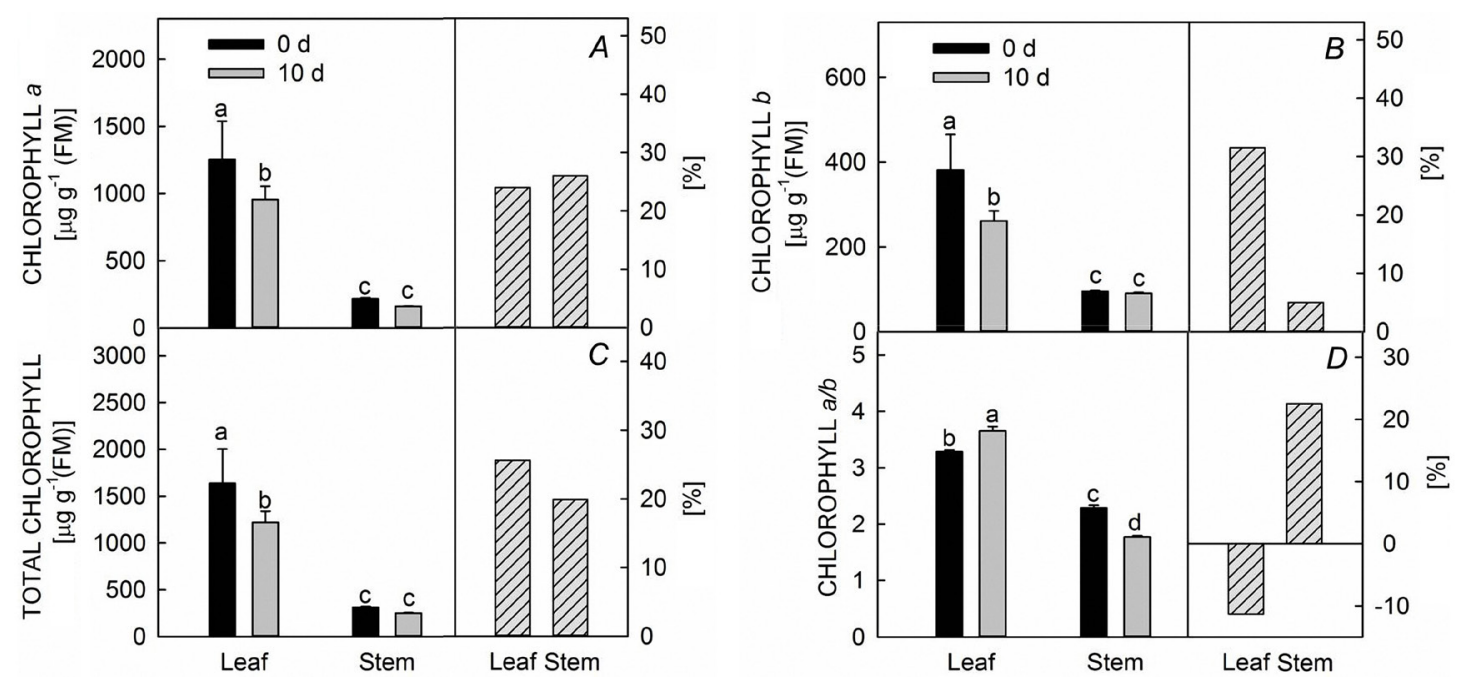

Fig. 3. Changes in the chlorophyll $a(A)$, chlorophyll $b(B)$, total chlorophylls $(C)$ content as well as the chlorophyll $a / b$ ratio $(D)$ of leaves and stems of Paederia scandens under low temperature for 0 and $10 \mathrm{~d}\left(\mathrm{~T}=16^{\circ} \mathrm{C}\right)($ left $)$, and comparison of the increased percentage in chlorophyll contents of the leaves and stems under low-temperature treatment for $10 \mathrm{~d}($ right $)$. Values are means $\pm \mathrm{SD}$ $(n=3)$. Statistical significance was determined using one-way ANOVA with Duncan's multiple comparison test $(p<0.05)$.

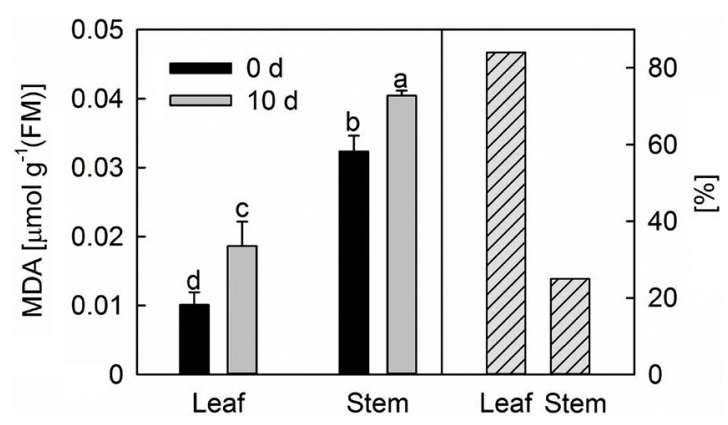

Fig. 4. The malondialdehyde (MDA) content in the leaves and stems of Paederia scandens under low temperature for 0 and 10 $\mathrm{d}\left(\mathrm{T}=16^{\circ} \mathrm{C}\right)($ left $)$, and comparison of the increased percentage in MDA contents of the leaves and stems under low-temperature treatment for $10 \mathrm{~d}$ (right). Values are means $\pm \mathrm{SD}(n=3)$. Statistical significance was determined using one-way ANOVA with Duncan's multiple comparison test $(p<0.05)$.
Soluble sugar content: As osmoprotectants, soluble sugar is a protective molecule in cells under temperature stress (Awasthi et al. 2015). The results showed that the contents of soluble sugar in the leaves and stems of P. scandens significantly increased after $10 \mathrm{~d}$; the content in the stems significantly increased by $118 \%$, which was nearly 10 times of that in the leaves (16\%) (Fig. 6).

\section{Discussion}

Temperature is a primary factor that affects plant growth and development. Plants have several adaptive mechanisms in response to certain adversities, such as low temperature and drought stress (Popov et al. 2010). Different organs of plants (stems and leaves) may also exhibit different physiological responses to cope with stress.

Low temperature can affect the photosynthesis of plants and reduce the utilization of light energy mainly because the 


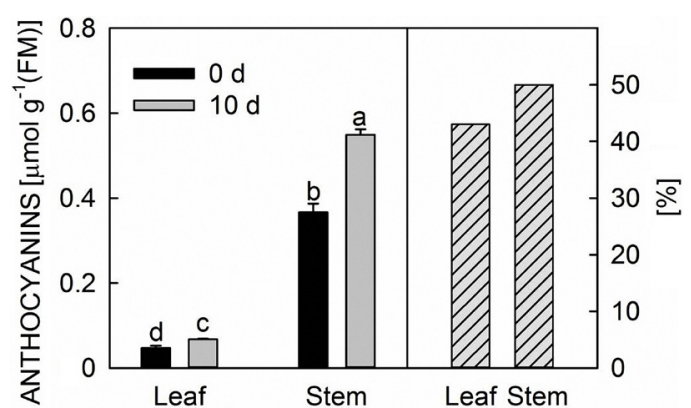

Fig. 5. Content of anthocyanins in the leaves and stems of Paederia scandens under low temperature for 0 and $10 \mathrm{~d}$ $\left(\mathrm{T}=16^{\circ} \mathrm{C}\right)($ left $)$ and a comparison of the increased percentage of anthocyanins contents of in the leaves and stems of plants under low temperature treatment for $10 \mathrm{~d}$ (right). Values are means $\pm \mathrm{SD}(n=3)$. Statistical significance was determined using one-way ANOVA with Duncan's multiple comparison test $(p<0.05)$.

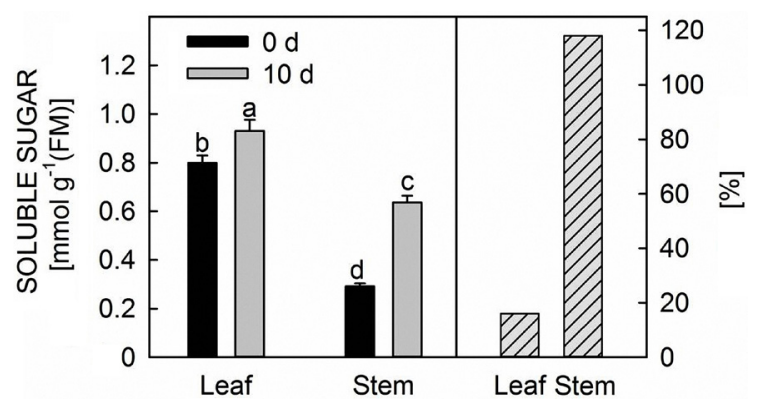

Fig. 6. The content of soluble sugars in the leaves and stems of Paederia scandens under low temperature for 0 and $10 \mathrm{~d}$ $\left(\mathrm{T}=16^{\circ} \mathrm{C}\right)($ left $)$ and a comparison of the increased percentage of soluble sugar contents in the leaves and stems of plants under low-temperature treatment for $10 \mathrm{~d}(r i g h t)$. Values are means $\pm \mathrm{SD}(n=3)$. Statistical significance was determined using one-way ANOVA with Duncan's multiple comparison test $(p<0.05)$.

Chl content is affected. The Chl-related indexes (including the Chl $a, \mathrm{Chl} b$, total Chl content) of the leaves and stems tended to decrease under low temperature, and the degree of decrease was much lower in the stems than that in the leaves (Fig. 3), indicating that the leaves were significantly more stressed than were the stems. Previous reports have also confirmed that the $\mathrm{Chl}$ content in plants decreases under low temperature (Borowski and Blamowski 2009). The results indicated that low temperature influences the synthesis of $\mathrm{Chl}$ by affecting the activity of enzymes, resulting in increased degradation of Chl (Glaszmann et al. 1990).

In plants, photosynthesis is a process that is highly sensitive to adversity. Changes in Chl fluorescence kinetic parameters can reflect all aspects of the effects of stress on photosynthesis (Fu et al. 2012). In our research, the $\Phi_{\text {PSII }}$ and ETR of the stems and leaves exhibited the same decreasing trend as did the $F_{v} / F_{m}$ under low temperature, but the decreases were stronger in the leaves than that in the stems (Fig. 2). These results suggested that low temperature inhibits PSII electron transfer, damaging the photosynthetic structure and blocking photosynthetic electron flow, resulting in a decrease in photosynthesis capability. Some studies have shown that the decrease in photosynthesis capability under low temperature may be due to the phase transition of thylakoid membrane lipids, leading to a decrease in thylakoid membrane fluidity (Öquist et al. 1983). Thus, overall, these phenomena inhibit the function of PSII by affecting the reaction center and light energy capture ability of thylakoid membrane, and the inhibition of photosynthesis in the leaves is more severe than that in stems.

The ability of plants to assimilate carbon for photosynthesis is weak under low temperature (Kubien and Sage 2004). Although Chl absorbs a small amount of light energy, photochemical processes can easily cause photoinhibition and increase the content of active oxygen, resulting in damage to the membrane system which can be assessed by MDA production (Hodges et al. 1999). In this study, we found that the MDA content in the leaves and stems after treatment increased significantly (Fig. 4), which indicated that both the leaves and stems suffered membrane lipid peroxidation, ion extravasation, and cell membrane system damage to a certain extent. These results were consistent with Zhang and Yang (2010) who reported that, compared with that under normal temperature, the MDA content in Microsorium pteropus under low temperature increased significantly. Therefore, compared to the leaves, the stems maintained relatively much stable and lower contents of $\mathrm{Chl}$ under low temperature, resulting in less active oxygen production and lower membrane peroxidation levels.

The production of ROS affects the normal growth of plants under low temperature. Plants can generally improve their resistance to adversity by inducing metabolic activities in their cells to adapt to low temperature and increase cold resistance at certain temperatures (Liu et al. 2013). Studies have shown that low temperature can induce anthocyanin accumulation (Chang et al. 1989, Carmona et al. 2017, Zhang et al. 2019). The results showed that the stems could accumulate more anthocyanins than the leaves (Fig. 5); the former of which could decrease light absorption and better remove ROS generated in plants (Zhu et al. 2018). These results were consistent with the findings by which the cold resistance of Begonia semperflorens obviously improved when the anthocyanin content increased (Zhang et al. 2019). In addition, the contents of soluble sugars in leaves and stems increased significantly under low temperature. Specifically, the increase of soluble sugar content in the stem was much greater than that in leaves (Fig. 6), which improved the low temperature tolerance of the stem. The increase of soluble sugar can increase the concentration of cell solution, decrease the water potential, and increase the water absorption capacity of plants, which helps alleviate the degree of cell damage at low temperature (O'Neill 1983, Sasaki et al. 1996). Several studies have shown that sugar has antioxidant effects in plants, especially as a scavenger of ROS at high concentrations (Couée et al. 2006, Awasthi et al. 2015). However, it is still necessary to 
study further its internal mechanism.

As an important economic and medicinal plant species, $P$. scandens exhibited similar trends in response to low temperature stress in its leaves and stems, although the stress was more severe in the leaves than that in the stems (Fig. 1). Both the stems and leaves have evolved several mechanisms to adapt the low temperature via enhanced contents of osmoprotectants and anthocyanins. In addition, the self-protection abilities were greater in the stems than that in the leaves. These results suggested that $P$. scandens is a kind of plant that can be propagated asexually by stem cuttings. Moreover, the stems were more tolerant than the leaves during winter and continued to grow normally (Fig. 1S, supplement). These findings could provide theoretical guidance for the study of stem tolerance of clonal propagation plants in the future, especially for invasive plants, which could effectively prevent and control plant invasion.

\section{References}

Aschan G., Pfanz H.: Non-foliar photosynthesis - a strategy of additional carbon acquisition. - Flora 198: 81-97, 2003.

Awasthi R., Bhandari K., Nayyar H.: Temperature stress and redox homeostasis in agricultural crops. - Front. Env. Sci. 3: 11, 2015.

Borowski E., Blamowski Z.K.: The effects of triacontanol 'TRIA' and Asahi SL on the development and metabolic activity of sweet basil (Ocimum basilicum L.) plants treated with chilling. - Folia Hortic. 21: 39-48, 2009.

Bressan R., Bohnert H., Zhu J.K.: Abiotic stress tolerance: from gene discovery in model organisms to crop improvement. Mol. Plant 2: 1-2, 2009.

Carmona L., Alquézar B., Marques V.V., Peña L.: Anthocyanin biosynthesis and accumulation in blood oranges during postharvest storage at different low temperatures. - Food Chem. 237: 7-14, 2017.

Chang K.G., Fechner G.H., Schroeder H.A.: Anthocyanins in autumn leaves of quaking aspen in Colorado. - For. Sci. 35: 229-236, 1989.

Chen W.P., Li P.H., Chen T.H.H.: Glycinebetaine increases chilling tolerance and reduces chilling-induced lipid peroxidation in Zea mays. - Plant Cell Environ. 23: 609-618, 2000.

Chen Z., Kolb T.E., Clancy K.M.: Mechanisms of Douglas-fir resistance to western spruce budworm defoliation: bud burst phenology, photosynthetic compensation and growth rate. Tree Physiol. 21: 1159-1169, 2001.

Couée I., Sulmon C., Gouesbet G., El Amrani A.: Involvement of soluble sugars in reactive oxygen species balance and responses to oxidative stress in plants. - J. Exp. Bot. 57: 449459, 2006.

Cui B., Cheng S.L., Yuan X.Y. et al.: [Effects of low temperature stress on the photosynthetic characteristics and chlorophyll fluorescence parameters of Bletilla striata.] - Chin. J. Trop. Crops 40: 891-897, 2019. [In Chinese] doi: 10.3969/ j.issn.1000-2561.2019.05.009.

de Zelicourt A., Colcombet J., Hirt H.: The role of MAPK modules and ABA during abiotic stress signaling. - Trends Plant Sci. 21: 677-685, 2016.

Fu W., Li P., Wu Y.: Effects of different light intensities on chlorophyll fluorescence characteristics and yield in lettuce. Sci. Hortic.-Amsterdam 135: 45-51, 2012.

Genty B., Briantais J.M., Baker N.R.: The relationship between the quantum yield of photosynthetic electron transport and quenching of chlorophyll fluorescence. - BBA-Gen. Subjects 990: 87-92, 1989.

Glaszmann J.C., Kaw R.N., Khush G.S.: Genetic divergence among cold tolerant rices (Oryza sativa L). - Euphytica 45: 95-104, 1990.

Hatfield J.L., Prueger J.H.: Temperature extremes: effect on plant growth and development. - Weather Clim. Extrem. 10: 4-10, 2015.

He Y.H., Guo L.S., Tian Y.L.: [Photosynthetic rates and chlorophyll fluorescence of Nitraria tangutorum at different leaf water potentials.] - Acta Bot. Bor.-Occident. Sin. 25: 2226-2233, 2005. [In Chinese] doi: 10.3321/j.issn:10004025.2005.11.016.

Hodges D.M., DeLong J.M., Forney C.F., Prange R.K.: Improving the thiobarbituric acid-reactive-substances assay for estimating lipid peroxidation in plant tissues containing anthocyanin and other interfering compounds. - Planta 207: 604-611, 1999.

Korn M., Gärtner T., Erban A. et al.: Predicting Arabidopsis freezing tolerance and heterosis in freezing tolerance from metabolite composition. - Mol. Plant 3: 224-235, 2010.

Kubien D.S., Sage R.F.: Low-temperature photosynthetic performance of $\mathrm{a} \mathrm{C}_{4}$ grass and a co-occurring $\mathrm{C}_{3}$ grass native to high latitudes. - Plant Cell Environ. 27: 907-916, 2004.

Kuk Y.I., Shin J.S., Jung H.I. et al.: Mechanism of paraquat tolerance in cucumber leaves of various ages. - Weed Sci. 54: 6-15, 2006.

Liu W., Yu K., He T. et al.: The low temperature induced physiological responses of Avena nuda L., a cold-tolerant plant species. - Sci. World J. 2013: 658793, 2013.

Liu W.Y., Zhang Y.F., Zhang D.X.: [Study on cold resistant genes in plants.] - J. Shanxi Datong Normal Univ. Nat. Sci. Ed. 28: 52-55, 2012. [In Chinese] doi: 10.3969/j.issn.16740874.2012.06.019.

Lu L.H., Hu Y.K., Li Y.M.: [Free proline accumulation dynamics of two wheat cultivars with different drought-resistance under water stress.] - Acta Agric. Bor.-Sin. 21: 75-78, 2006. [In Chinese] doi: 10.3321/j.issn.1000-7091.2006.02.018.

Ma Y., Mao Y., Fu J.X.: [Study on the composition of the volatile oil from Paederia scandens.] - Acta Bot. Bor.-Occident. Sin. 20: 145-148, 2000. [In Chinese] doi: 10.3321/j.issn.10004025.2000.01.023.

Melis M., Spangfort M., Andersson B.: Light-absorption and electron-transport balance between photosystem II and photosystem I in spinach chloroplasts. - Photochem. Photobiol. 45: 129-136, 1987.

Nariyuki I., Yang Z.Q., Yoshitama K., Kurosawa K.: Flavonol glycosides from Paederia scandens var. mairei. Z. Naturforsch. 45: 1081-1084, 1990.

O'Neill S.D.: Osmotic adjustment and the development of freezing resistance in Fragaria virginiana. - Plant Physiol. 72: 938-944, 1983.

Öquist G.: Effects of low temperature on photosynthesis. - Plant Cell Environ. 6: 281-300, 1983.

Oxborough K., Baker N.R.: Resolving chlorophyll $a$ fluorescence images of photosynthetic efficiency into photo-chemical and non-photochemical components-calculation of $\mathrm{q}_{\mathrm{p}}$ and $\mathrm{F}_{\mathrm{v}}{ }^{\prime} / \mathrm{F}_{\mathrm{m}}{ }^{\prime}$ without measuring $\mathrm{F}_{0}{ }^{\prime}$. - Photosynth. Res. 54: 135-142, 1997.

Popov V.N., Antipina O.V., Trunova T.I.: Lipid peroxidation during low-temperature adaptation of cold-sensitive tobacco leaves and roots. - Russ. J. Plant Physl+ 57: 144-147, 2010.

Sanghera G.S., Wani S.H., Hussain W., Singh N.B.: Engineering cold stress tolerance in crop plants. - Curr. Genomics 12: 3043, 2011.

Sasaki H., Ichimura K., Oda M.: Changes in sugar content during cold acclimation and deacclimation of cabbage seedlings. - 
Ann. Bot.-London 78: 365-369, 1996.

Shahandashti S.S.K., Amiri R.M., Zeinali H., Ramezanpour S.S.: Change in membrane fatty acid compositions and coldinduced responses in chickpea. - Mol. Biol. Rep. 40: 893-903, 2013.

Sharma E., Sharma R., Borah P. et al.: Emerging roles of auxin in abiotic stress responses. - In: Pandey G.K. (ed.): Elucidation of abiotic stress signaling in plants: Functional genomics perspectives. Pp. 299-328. Springer, New York 2015.

Sun Q.F., Yu X.C., Gao J.J. et al.: [Effect of carboxymethyl chitosan on chilling tolerance in cucumber seedlings.] - Sci. Agr. Sin. 37: 1660-1665, 2004. [In Chinese] doi: 10.3321/j. issn:0578-1752.2004.11.013

Tambussi E.A., Bort J., Guiamet J.J. et al.: The photosynthetic role of ears in $\mathrm{C}_{3}$ cereals: metabolism, water use efficiency and contribution to grain yield. - Crit. Rev. Plant Sci. 26: $1-16,2007$.

Vágújfalvi A., Kerepesi I., Galiba G. et al.: Frost hardiness depending on carbohydrate changes during cold acclimation in wheat. - Plant Sci. 144: 85-92, 1999.

Vanderklein D.W, Reich P.B.: European larch and eastern white pine respond similarly during three years of partial defoliation.Tree Physiol. 20: 283-287, 2000.

Wellburn A.R.: The spectral determination of chlorophylls $a$ and $b$, as well as total carotenoids, using various solvents with spectrophotometers of different resolution. - J. Plant Physiol. 144: 307-313, 1994.

Wu X.X., Zha D.S., Tai X.: [Effects of low temperature stress on growth, activities of antioxidant enzymes and osmotic substance of eggplant seedlings.] - Jiangsu J. Agric. Sci. 24: 471-475, 2008. [In Chinese] doi: 10.3969/j.issn.10004440.2008.04.018.

Xu W., Rosenow D.T., Nguyen H.T.: Stay green trait in grain sorghum: relationship between visual rating and leaf chlorophyll concentration. - Plant Breeding 119: 365-367, 2000.

Yang F.J., He H.S., Wang W.J. et al.: [Different characteristics of photosynthesis in stems and leaves of Mikania micrantha.] Acta Phytoecol. Sin. 6: 998-1004, 2006. [In Chinese] doi: 10.17521/cjpe.2006.0128.

Yin G.H., Wang M.Y., Zhang H.C.: [GC-MS analysis of essential oil of leaves in Paederia scandens with supercritical $\mathrm{CO}_{2}$ extraction.] - Food Sci. Tech. 12: 303-304, 2009. [In Chinese] doi: 10.3321/j.issn:1001-4454.2001.11.012.

Zhan D.X., Yang Y., Hu Y.Y. et al.: Contributions of nonleaf organs to the yield of cotton grown with different water supply. - Sci. World J. 2014: 602747, 2014.

Zhang J.C., Yang D.H.: [Activity of SOD, CAT, POD and content of MDA in Microsorium pteropus caused by glyphosate stress at normal and low temperature.] - Natur. Sci. J. Harbin Normal Univ. 26: 90-93, 2010. [In Chinese] doi: 10.3969/ j.issn.1000-5617.2010.04.029.

Zhang Q., Zhai J.J., Shao L. et al.: Accumulation of anthocyanins: An adaptation strategy of Mikania micrantha to low temperature in winter. - Front. Plant Sci. 10: 1049, 2019.

Zhang S.X.: [Analysis of nutritional components of Paederia scandens.] - Food Res. Dev. 3: 154-155, 2006. [In Chinese] doi: 10.3969/j.issn.1005-6521.2006.03.058.

Zhang T.J., Chow W.S., Liu X.T. et al.: A magic red coat on the surface of young leaves: anthocyanins distributed in trichome layer protect Castanopsis fissa leaves from photoinhibition. Tree Physiol. 36: 1296-1306, 2016.

Zhao S.J., Xu C.C., Zou Q. et al.: [Improvements of method for measurement of malondialdehyde in plant tissues.] - Plant Physiol. Commun. 30: 207-210, 1994. [In Chinese] doi: 10.13592/j.cnki.ppj.1994.03.016.

Zhu H., Zhang T.J., Zheng J. et al.: Anthocyanins function as a light attenuator to compensate for insufficient photoprotection mediated by nonphotochemical quenching in young leaves of Acmena acuminatissima in winter. - Photosynthetica 56: 445-454, 2018.

Zwack P.J., Rashotte A.M.: Interactions between cytokinin signalling and abiotic stress responses. - J. Exp. Bot. 66: 4863-4871, 2015.

(C) The authors. This is an open access article distributed under the terms of the Creative Commons BY-NC-ND Licence. 